\title{
Erratum zu: Analyse der Technikbereitschaft und -nutzung von Pflegeinnovationstechnologien von Mitarbeiter*innen im Pflegeprozess
}

\author{
Redaktion „HeilberufeScience“1 \\ Online publiziert: 3. November 2020 \\ ๑) Springer-Verlag GmbH Austria, ein Teil von Springer Nature 2020
}

\section{Erratum zu:}

\section{HBScience 2020}

https://doi.org/10.1007/s16024-020-00339-3

In der Originalpublikation des Beitrags kam es leider zu einem Fehler.

Das Eingangsdatum war inkorrekt. Das korrekte Datum lautet: 13. Mai 2019.

Wir bitten, die Korrektur zu beachten und den Fehler zu entschuldigen.

Die Redaktion

Die Online-Version des Originalartikels ist unter https://doi.org/ 10.1007/s16024-020-00339-3 zu finden.

Redaktion „HeilberufeScience“

heilberufescience@springer.com

1 Springer-Verlag GmbH, Wien, Österreich 